ISSN : $1829-8257$

STAIN Palangka Raya

\title{
Bahasa Agama dalam Wacana Sosiologi Agama
}

\author{
Ali Audah \\ Universitas Ahmad Dahlan Yogyakarta \\ aliaudah@gmail.com
}

\begin{abstract}
A short study of the history of the sociology of religion is enough to show the importance of religion as a factor relevant to the study of variations, maintenance, language policy and planning are already equipped to work at least some of them are generally regarded as the founder of a branch of linguistics. However, these effects do not stop merely linguistic region but also on the dimensions of the broader culture . Claiming Arabic is the only language of Islam becomes simpler if it is associated with the contestation countries that historically have been quite dominant in the development of Islam. As a sociological study of religion, it has become wide open land research to continue to be observed in the level of practice speaking societies where Islam is the majority religion
\end{abstract}

Keywords: relegion of linguistic, perspektive, religion of social

\section{A. Pendahuluan}

Bahasa bukanlah instrumen netral yang kita gunakan untuk menafsirkan dunia secara impersonal dan obyektif karena bahasa mempunyai sifat bawaan yang bias. Bahasa mempunyai banyak sisi yang cukup kompleks ketika dilihat sebagai alat untuk menyatakan gagasan atau keinginan, yang bersifat amat individualistik (James, W. 1902, dikutip dari Wallace $1966^{1}$. Teori ini yang menerangkan tentang bagaimana bahasa mempengaruhi cara manusia melihat dunia pertama kali dikemukakan oleh antropolog Amerika dan ahli bahasa Edward Sapir pada tahun 1929 dan kemudian disempurnakan oleh muridnya, Benjamin Lee Whorf ${ }^{2}$.

Sebagai salah satu bentuk atau ragam bahasa, Bahasa Agama menawarkan teori inovatif agama sebagai kelas representasi budaya, tergantung pada bahasa untuk menyatukan beragam kapasitas pikiran manusia. Kajian mengenai hal ini juga telah

\footnotetext{
${ }^{1}$ Wallace AFC. 1966. Religion: An AnthropologicalView. New York: Random House, 55.

${ }^{2}$ Phyllis Ghim-Lian Chew. 2006. Language Use and Religious Practice:The Case of Singapore. In: Explorations in the Sociology of Language and Religion. John Benjamins Publishing Company, Amsterdam/Philadelphia: 213-234
} 
memperkaya teori linguistik, berdasarkan bagaimana ucapan dipahami, metafisik dan moral yang misteri dan peran kunci mereka dalam pikiran dan tindakan ${ }^{3}$.

Di Amerika Serikat Fakta dimana secara filosofis orang terhormat dapat memiliki ketidaksepakatan serius atas agama memainkan peranan penting dalam suatu hal umum, kehidupan publik. Alasan pembenaran yang dicari dari agama telah digunakan untuk mendukung lembaga-lembaga dan praktik hukum, dan untuk menentang ide lain yang berbeda, meliputi hampir setiap bidang kehidupan . masa kini wilayah yang kerap dipublikasikan untuk pertukaran isu agama - politik melibatkan aborsi (atau " reproduksi hak "), euthanasia dan bunuh diri, hukuman mati, pernikahan, seksetika, rekayasa genetika, pendidikan (pendidikan agama sekuler vs ;juga, khususnya instruksi dalam ilmu dan sejarah dimana ini melibatkan agama atau sekuler indoktrinasi), status pajak dari agama lembaga, dan penggunaan praktik-praktik keagamaan dan simbol dalam pemerintahan ${ }^{4}$.

Bahasa memang bisa mengambil dimensi spiritual yang berbeda. Bahkan, memainkan peran penting dalam ekspresi keagamaan apakah orang percaya adalah monolingual atau multi bahasa. Ketika orang tersebut adalah pengguna dua bahasa (bilingual) atau multi bahasa, mereka memiliki akses dalam jumlah yang lebih besar dari sumber linguistik Anya Woods ${ }^{5}$. Namun, Smolicz ${ }^{6}$ telah mengingatkan bahwa: Dalam hal bahasa, individu dapat menjadi bilingual, trilingual atau multi bahasa, tetapi mereka tidak bisa mengklaim sebagai bi-agama atau multi-agama dalam iman dan doktrin.

\footnotetext{
${ }^{3}$ Downes, W. 2011.Language and Religion: A Journey into the Human Mind, Cambridge University Press, New York

${ }^{4}$ Taliaferro, C. 2005. Evidence and Faith: Philosophy and Religion since the Seventeenth Century. New York: Cambridge University Press, 425.

${ }^{5}$ Woods, A. 2004.Medium or Message?Language and Faith in Ethnic Churches.Multilingual Matters Ltd, Clevedon, Buffalo, Toronto, Sydney, 13.

${ }^{6}$ Smolicz, J.J. 1994. Multiculturalism, Religion and Education.Education and Society.12(1): 38.
} 
Sebuah produk inti dari irisan bahasa dan agama adalah bahasa agama. Istilah ini telah dipahami secara berbeda dalam berbagai disiplin ilmu. Rajeshwari V. Pandharipande, menggambarkan situasi ini dalam pernyataan berikut:

For example, sociolinguists treat language of religion as a register of a natural language, which they perceive as a system or a resource from which utterances are composed (Samarin 1976). In linguists'view, what separates language of religion from its non-religious counterpart is the selection of linguistic material at different levels (lexical, syntactic, phonological, semantic, stylistic, etc.) in the religious register. A theologian, on the other hand, may treat language of religion as a construct of thoughts which is different from its non-religious counterpart, and which is expressed through various linguistic structures ${ }^{7}$.

Iman dan bahasa adalah alat bagi manusia, simbol dari ekspresi dan petunjuk pengetahuan dan perilaku mereka. Mereka menggunakan iman sebagai keyakinan bawaan mereka dan menggunakan bahasa sebagai medium untuk mengekspresikan keyakinan. Bahasa meliputi tidak hanya spesifik bahasa sejarah, tidak hanya prinsipprinsip universal fonologi, sintaksis dan leksikon, tidak hanya bagaimana prinsipprinsip ini muncul dan digunakan dalam pikiran atau otak, tapi bagaimana bahasa digunakan untuk berkomunikasi pesan dan untuk melakukan tindakan dalam berbagai register: berdoa, untuk terlibat dengan khutbah, untuk mempelajari kitab suci, untuk berpartisipasi dalam liturgi atau mendiskusikan teologi, dan sebagainya William Downes $^{8}$. Namun, seperti yang dibahas oleh David Cristal ${ }^{9}$, masalah muncul terutama ketika bahasa (atau gaya) memiliki status resmi. Apakah Islam memiliki bahasa resmi? Jika demikian, apa itu? Bagaimana bahasa lain? Ada banyak pertanyaanpertanyaan berikut lain yang berasal dari materi ini.

${ }^{7}$ Pandharipande, Authenticating a Tradition in Transition: Language of Hinduism in the US. In: Omoniyi, T. (ed.). 2010. The Sociology of Language and Religion: Change, Conflict and Accommodation. Palgrave Macmillan, New York, 58-83.

${ }^{8}$ Downes, W. 2011, Op. Cit. 20.

${ }^{9}$ Crystal, D. 1966. Language and Religion. In L. Sheppard (ed), Twentieth century Catholicism. Hawthorn Books, New York, 11-28. 
ISSN : $1829-8257$

STAIN Palangka Raya

\section{B. Kajian Pustaka}

Umumnya, bahasa agama dapat dibagi menjadi tiga komponen: bentuk bahasa, isi (kandungan) agama dan penggunaan atau fungsi ${ }^{10}$. Ketiga komponen ini dapat menjadi penentu atau pembeda identitas agama atau setidaknya dapat menggambarkan karakteristik pemeluk suatu agama.

Sosiiolog dari bahasa dan agama berpendapat bahwa bahasa, yang telah diabaikan oleh para sarjana studi agama, adalah variabel paling jelas yang menunjukkan identitas agama ${ }^{11}$ Fishman menulis :

Among the founders of modern sociology, Max Weber and Emile Durkheim., were quite clearly very much interested in religion (note, e.g., Weber's Sociology of Religion [tr. 1963], and Durkheim's. clear demonstration that all social norms are essentially "religious in nature in his Elements of the Religious Life [ tr. 1915]). Among the founders of the modern sociology of language, Charles Ferguson stands out for repeatedly stressing the centrality of religion in connection with understanding such central sociolinguistic topics as diglossia (1959) and language planning (1968), as well as in connection with his groundbreaking inquiries in many major areas of the world (e.g., 1969 and across centuries and millennia $(1982,1986)$

Sebuah artikel yang ditulis oleh Coffin dan Coffindan O, Halloran (2005) benar-benar menjelaskan bagaimana bahasa digunakan untuk kepentingan menyatakan ekspresi keagamaan:

1. Mengenang (reminiscing): kata-kata yang mampu membawa peristiwa masa lalu ke dalam pikiran. Contoh: Berdoa di awal dan akhir hari.

2. Menyembah (worshiping): Tindakan atau kegiatan penting ibadah yang berlangsung dengan sangat sedikit kata-kata. Contoh: Kata-kata Quran dilukis di kendaraan sebagai jimat atau pegangan atau memadamkan lilin pada altar dalam

\footnotetext{
${ }^{10}$ Pandharipande, 2006. Ideology, Authority, and Language Choice: Language of Religion in South Asia. In: Explorations in the Sociology of Language and Religion. John Benjamins Publishing Company, Amsterdam/Philadelphia: 142.

${ }_{11}$ Rajah-Carrim, A. 2010.Mauritian Muslims: Negotiating Changing Identities through Language. In: Omoniyi, T. (ed.). The Sociology of Language and Religion: Change, Conflict and Accommodation. Palgrave Macmillan, New York: 29-44
} 
ISSN : $1829-8257$

STAIN Palangka Raya

liturgi Ortodoks atau mendistribusikan makanan tradisional di Yahudi dan operasi lainnya dilakukan melalui kata-kata operatif

3. Memberi komitmen untuk melaklukan suatu tindakan tertentu atau bernazar (committing): Contoh: Dalam raja Israel terikat untuk tuan kekaisaran mereka berdasarkan perjanjian mereka membentuk yang terikat untuk yang Ilahi Raja, Yahweh. Imam Ali berkomitmen dan dibatasi dirinya untuk Muhammad dan tidak pernah melanggar perjanjian-Nya sampai akhir hidupnya.

4. Mengucapkan kata-kata berkat (solemnizing): menggunakan kata-kata agama memiliki efek kejadian alam. Contoh: Menggunakan Bismillah (Dengan nama Allah) setiap kali umat Islam ingin memulai baruaksi. Demikian pula hadir dalam Kristen dengan mengatakan dalam nama Bapa, dan dari Anak dan Roh Kudus.

5. Meminjam, berdoa, berkat: Mengajukan pertanyaan atau membuat permintaan (bahkan mereka memberikan sesuatu untuk satu sama lain). Contoh: Allah menyertai kamu, Tuhan memberkati anda dan lainnya yang sejenis.

6. Menasihati (exhorting): Mendesak atau mendorong orang lain untuk bergabung dengan kegiatan agama atau memuja. Contoh: Dalam al-Quran, Surah Ali Imran, ayat 125 dorongan dan mendesak orang untuk menjadi saleh dan mereka akan diberikan lima ribu malaikat untuk melindungi mereka dari kejahatan.

7. Mengilhami atau menginspirasi (inspiring): Menggunakan kata-kata untuk membangkitkan perasaan dan merangsang tindakan. Contoh: kehendak sosial dan politik Imam Khomeini di akhir hidupnya adalah sebuah manifesto untuk membangkitkan perasaan dan menginspirasi orang mendukung Islam dan Iran.

\section{Metode Penelitian}

Penelitian ini merupakan penelitian bahasa dan kaitannya dengan sosiologi agama. Oleh karena itu, pendekatan yang dilakukan dalam penelitian ini adalah pendekat Sosiolinguistik yakni menkaji hubungan bahasa dan masyarakat yang mengaitkan dua bidang yang dapat dikaji secara terpisah yaitu struktur formal bahasa oleh linguistik dan struktur masyarakat oleh sosiologi. 
ISSN : $1829-8257$

STAIN Palangka Raya

\section{Pembahasan}

Bahasa Arab Klasik adalah bahasa yang digunakan dalam naskah al-Qur'an. Ini membuat Arab menjadi sangat erat kaitannya dengan agama Islam karena alQur'an diturunkan dalam bahasa Arab. Sebagaimana bahasa Ibrani adalah bahasa yang paling suci dalam agama Yahudi, bahasa Sansekerta untuk Hindu, maka bahasa Arab adalah bahasa yang paling suci dalam Islam. Arab Klasik - bahasa al-Qur'an awalnya merupakan dialek Mekah di tempat yang sekarang menjadi wilayah Kerajaan Arab Saudi. Oleh karena itu, adalah menjadi sebuah keyakinan pokok bagi muslim pada umumnya bahwa bahwa yang disebut sebagai al-Qurān adalah al-Qurān yang ditulis dalam bahasa Arab. Ketika diterjemahkan ke dalam bahasa selain Arab maka ia berhenti menjadi "kata-kata Allah yang suci" dan berkedudukan hanya sebagai sebuah tafsiran atas naskah aslinya yang berbahasa Arab. Untuk alasan ini, setiap kali umat Islam membaca al-Qurān dalam doa ritual atau format liturgis lainnya, mereka selalu membacanya dalam bahasa Arab. Jadi, dapatkah kita simpulkan bahwa bahasa Islam adalah bahasa Arab klasik? ${ }^{12}$

Syaikh al-Islam Ibnu Taimiyah (semoga Allah merahmatinya) di Iqtidaa'usSiraatil-Mustaqiem (2: 207) mengatakan bahwa bahasa Arab itu sendiri adalah bagian dari Islam, dan mengetahui bahasa Arab merupakan kewajiban. Jika itu adalah tugas untuk memahami al-Qur'an dan Sunnah, dan mereka tidak dapat dipahami tanpa mengetahui bahasa Arab, maka berarti yang diperlukan untuk memenuhi tugas juga wajib. Namun, dalam kasus ucapan seseorang, Muslim harus selalu menggunakan ucapan Islam 'As-salaam alaikum ', atau apakah diperbolehkan untuk menggunakan salam lain seperti 'Selamat Pagi '"? Gus Dur dan KH. AR Fakhruddin, dua mantan pemimpin gerakan Islam di Indonesia, melihat bahwa salam Indonesia atau Jawa dapat digunakan untuk menggantikan salam Islam.

\footnotetext{
${ }^{12}$ McAuliffe,J. D. 2001. Preface. In: McAuliffe,J. D., et.al (eds.). Encyclopaedia of the Qur_ān: Volume One A-D. Brill, Leiden-Boston-Koln: i-xiii
} 
Dan bagaimana jika kita berlatih berdoa dalam bahasa lain? Untuk Dr. Muhammad Abdul Munim Khan (2011), bahasa Arab adalah bahasa berdoa, tetapi Syaikh al-Islam Ibnu Taimiyah dalam Al-Fatawa al-Kubra, (2: 425) memiliki pendapat bahwa diizinkan untuk membuat do'a 'dalam bahasa Arab atau dalam bahasa lain selain bahasa Arab. "Allah tahu keinginan orang yang membuat do'a, bahkan jika ia tidak dapat berbicara bahasa Arab dengan benar, karena dia mengerti semua bahasa dan mengerti kebutuhan mereka yang berbicara bahasa yang berbeda. Syaikh al-Islam Ibnu Taimiyyah juga pernah ditanya pertanyaan berikut: "Bagaimana akan orang-orang ditangani pada hari kiamat? Allah akan membahas mereka dalam bahasa Arab? Apakah benar bahwa bahasa orang-orang neraka akan Farsi dan bahasa rakyat Paradise akan bahasa Arab? "Ditulis pada Majmu 'Fatawa al-(4/300), ia menjawab pertanyaan sebagai berikut (Syaikh Muhammad S Al-Munajjid (b) 2011):

It is not known which language the people will speak on that Day or in which language they will hear the words of the Lord, may He be glorified and exalted, because Allaah has not told us anything about that, and neither has His Messenger (peace and blessings of Allaah be upon him). It is not true that Farsi is the language of the people of Hell or that Arabic is the language of the people of Paradise. We do not know of any dispute concerning that among the Sahaabah (may Allaah be pleased with them); rather they all refrained from discussing that, because discussing such matters is unnecessary talk. But there was a dispute concerning that among later scholars. Some people said that they will speak in Arabic, and others said: Except the people of Hell, who will answer in Farsi, which will be their language in Hell. Others said: They will be speak in Syriac, because it is the language of Adam, and from it all other languages stemmed. Others said: Except the people of Paradise, who will speak Arabic. None of the proponents of these arguments have any evidence, whether based on reason or textual evidence. Rather they are claims that are devoid of any evidence. Allaah knows best and is Most Wise.

Sebuah kasus di Mauritius, sebuah negara pasca-kolonial 600 kilometer timur Madagaskar, membuktikan bahwa iman yang berbeda dalam bahasa Islam telah membedakan atau menjadi identitas agama dari kelompok teologis yang berbeda: Ahlus Sunnah dan Deobandis. Ahlus-Sunnah berhubungan dengan bahasa Urdu dan 
Deobandis dengan Arab. pengikut Ahlus-Sunnah melihat benua India sebagai situs kehidupan Muslim dan keaslian Islam dan mendukung studi Urdu sebagai " budaya Islam " dari Mauritians asal India ' ( Eisenlohr 2006: 402 ). Kaum Deobandis menentang promosi Urdu dengan alasan bahwa itu adalah bahasa agama budaya dan tidak Islami . Mereka percaya bahwa bahasa Arab adalah bahasa Islam dan harus dipromosikan terlepas dari latar belakang etnis Muslim ' (Aaliya Rajah - Carrim ${ }^{13}$. Di sini, bahasa berfungsi sebagai sarana fundamental yang memisahkan kelompokkelompok teologis ( Eisenlohr 2006) .

Sejumlah penelitian di salah satu daerah di Nigeria bernama Yoruba menunjukkan bahwa Islam, melalui bahasa Arab, tidak hanya berdampak pada leksikon Yoruba tetapi juga telah menyebabkan perubahan dalam pandangan dunia penduduk Yoruba. Penelitian telah menunjukkan dampak ini pada fonetik, fonologi serta struktur leksikal dari bahasa Yoruba (lihat misalnya, Abdul 1976, Ogunbiyi 1980, Abu Bakre 1984, Malik 1995), Hal ini dapat dilihat terutama dalam aspek penamaan mana pengaruh agama di Yoruba identitas pribadi sangat besar . Yorubameng konversi ke Islam menjatuhkan nama asli Yoruba mereka untuk berbahasa Arab nama-nama Islam. Meskipun nama-nama sejarah dan narasi sekitarnya masih sangat penting untuk Yoruba, dengan Islam beberapa upaya yang dibuat untuk berhubungan sejarah tersebut untuk kehidupan nabi terakhir atau penting kepribadian pada awal Islam. Perubahan ini akan, bagaimanapun, membuat hari ini lebih sulit untuk menjaga sejarah keluarga dan narasi dalam nama ${ }^{14}$.

Di Indonesia, sebuah penelitian sosiologis yang dilakukan oleh I Nyoman Adi Jaya Putra pada penggunaan kode oleh masyarakat tutur Muslim Pegayaman, Buleleng, Bali menemukan bahwa bahasa Bali (BB), Bahasa Indonesia (BI), dan Bahasa Lain Lain (BL dalam hal ini Bahasa Arab) adalah tiga kode utama yang yang

${ }^{13}$ Rajah-Carrim, A. 2010.Mauritian Muslims: Negotiating Changing Identities through Language. In: Omoniyi, T. (ed.). The Sociology of Language and Religion: Change, Conflict and Accommodation. Palgrave Macmillan, New York, 33.

${ }^{14}$ Salami, O. 2010.Arabic and Sociocultural Change among the Yoruba. Dalam: Omoniyi, T. (ed.). The Sociology of Language and Religion Change, Conflict and Accommodation. New York: Palgrave Macmillan. 56. 
digunakan, dan di antara mereka $\mathrm{BB}$ adalah kode yang dominan dipilih dan digunakan untuk berkomunikasi secara verbal. Ada situasi bahasa diglossic di masyarakat tutur ini, terutama ketika mereka berinteraksi secara lisan menggunakan BB, sehingga ada juga semacam kode pencampuran fenomena. Ini berarti bahwa orang dapat menjadi bilingual atau multi lingual dalam bahasa, tetapi tidak dalam agama. Putra ${ }^{15}$ mencatat:

Dari sejumlah kode yang dikuasai oleh masyarakat tutur ini, BB merupakan kode yang dominan dipilih dan digunakan terutama pada ranah-ranah keakraban seperti ranah keluarga,ranah ketetanggaan, dan ranah kekariban. Pada ranah transaksi, ranah pendidikan, dan ranah pemerintahan, BB juga banyak digunakan. Dan bahkan penggunaan BB telah merambah kepada ranah keagamaan. Temuan ini berbeda dengan temuan penelitian yang dilakukan Sumarsono (1990) di masyarakat Muslim Loloan, dan berbeda pula dengan hasil observasi yang peneliti lakukan di masyarakat Muslim Nyuling, Saren Jawa, dan Kampung Sindu di Karangasem. Pada masyarakat Muslim yang disebutkan ini BB tidak banyak digunakan pada ranah keagamaan. Penelitian yang mendalam perlu dilakukan di masyarakat-masyarakat tutur ini. Bagi masyarakat Muslim Loloan khususnya, BB diasosiasikan dengan Hindu dan karenanya BB tidak banyak digunakan.

Lebih lanjut dijelaskan bahwa:

Disimpulkan bahwa kausasi ultimat dari semua perilaku kebahasaan masyarakat tutur Muslim Pegayaman, (mulai dari memilih Bahasa Bali, menggunakannya dalam berinteraksi verbal, hingga mewariskannya), adalah untuk memaksimalkan fitness mempertahankan eksistensi "kebalian" mereka. Dengan berbahasa Bali, mereka pun ingin menunjukkan identitas kelompok (sosial atau etnis) mereka, danjuga identitas budaya mereka yang khas sebagai orang Muslim Pegayaman yang Bali. Baik sebagai individu maupun sebagai suatu komunitas, identitas semacam ini disadari sangat diperlukan untuk mempertahankan eksistensi mereka di tengah-tengah komunitas Bali non Muslim.

\footnotetext{
${ }^{15}$ Putra, I.N.A.J. 2009.The Use of Code by the Moslem Speech Community of Pegayaman: A Sociolinguistic Study. E-Journal of Linguistics, No. 1. Department of Linguistics, Faculty of Letters, Udayana University, Bali, 10.
} 
Di samping Bahasa Arab, Bahasa Turki dan Persia sebenarnya juga memegang peranan penting dalam sejarah ummat Islam.Kramer ${ }^{16}$ menulis:

Across the expanse of Islamic history, different Arabic, Persian, and Turkish terms have designated the political community and the state, rulers and ruled, varieties of wars and rebellions, and allies and enemies of the established order

Politik Islam dinyatakan tidak hanya dalam kosa kata yang berbeda tetapi juga dalam bahasa yang berbeda. Tata bahasa dan sintaksis dari wacana politik dalam Islam berbeda secara fundamental dari orang-orang dari tradisi politik lainnya, dan telah lama menjadi masalah yang cukup rumit di luar dialog yang terjadi dalam masyarakat muslim. Bahkan kata-kata yang diakui secara luas seperti jihad dan salam masih saja menimbulkan masalah pemahaman, yang diciptakan oleh cara bagaimana kata-kata tersebut telah diucapkan atau digunakan dalam praktek pembicaraan dalam sejarah, dalam konsepsi Islam mengenai perang dan perdamaian, dan sebagai dampak dari ide-ide barat terhadap Islam ${ }^{17}$. Bahkan untuk kondisi saat ini, ketiga negara (Arab Saudi yang merepresentasikan bahasa Arab; Iran yang merepresentasikan bahasa Parsi dan Turki yang merepresentasikan bahasa Turki) saling bersaing di wilayah budaya populer melalui media film dan sinetron bahkan fashion. Namun, tak bisa dipungkiri kenyataan sejarahnya bahwa bagaimanapun kedua bahasa tersebut telah dipengaruhi oleh kebudayaan Arab yang Islam terlebih dahulu sebelum kemudian menjadi bahasa yang mempunyai posisi kuat di beberapa wilayah Islam. Elwell-Sutton (1986: 233) mencatat bahwa, “ ...the most significant impact of Arabic on Persian has been in the expansion of vocabulary, a process that seems scarcely to be complete even at the present day." Menurut Bahar ${ }^{18}$ proses dimulai dengan katakata, terutama kata-kata yang bersifat administratif atau agama, yang tidak dapat ditemukan kesepadanannya dalam bahasa Persia.

\footnotetext{
${ }^{16}$ Kramer, M.1989.The Political Language of Islam. Middle East Review: 63-64.

${ }^{17}$ Kramer, M.1989, Ibid., 63.

${ }^{18}$ Bahar. M.T.1942. Sabk Shinasi (A Study of Styles). 3 vols. Tehran, 256.
} 
Bagaimana dengan bahasa Turki? bahasa Turki dituturkan di wilayah geografis yang luas di Eropa dan Asia. Bahasa ini tersebar di Azeri, Turkmenistan , Tartar, Uzbekistan, Baskurti, Nogay, Kyrgyztan, Kazakhstan, Yakuti, Cuvas dan dialek lainnya. Bahasa Turki merupakan cabang Altai dari keluarga bahasa UralAltai, dan dengan demikian berkaitan erat dengan bahasa-bahasa di Mongolia, Manchu - Tungus, Korea, bahkan mungkin Jepang.

Dalam sejarah abad pertengahan Hindustan, suku Turki memainkan peran utama di antara menaklukkan Muslim dan penguasa yang datang dan membuat India menjadi rumah mereka. Penduduk Turki dimulai pada paruh pertama abad ke-11 oleh Abu Mansur Sabuktigin dan proses pembentukan kerajaan mereka di North \& Barat Hindustan mulai dari akhir abad ke-12. Meskipun Sindh ditaklukkan oleh orang Arab, segera setelah pembentukan Abbasid Khalifah di abad ke-8 Masehi, ini dapat dimainkan secara langsung hanya peran marjinal dalam mempengaruhi budaya dan peradaban Hindustan. K.Gajendra Singh (2012) menulis sebagai berikut:

Sangat menarik bahwa dalam Malayalam (bahasa Kerala), Hindustani dikenal sebagai Tuluk Bhasha dan kata Tulukan digunakan untuk Muslim dan Tulukachi untuk wanita Muslim. Bahasa yang dipakai oleh orang-orang dari Turki disebut Tuluk Bhasha. Hal ini menarik karena hubungan antara pantai Kerala dan dunia Arab mendahului Islam dan telah interaksi yang konstan antara pantai Malabar Kerala dan dunia Arab tapi masih kata untuk seorang Muslim adalah Tulukan.

\section{E. Kesimpulan}

Kajian singkat pada sejarah sosiologi agama cukup untuk menunjukkan betapa pentingnya agama sebagai faktor yang relevan dengan studi variasi, pemeliharaan, kebijakan dan perencanaan bahasa yang sudah dilengkapi dalam karya setidaknya beberapa dari mereka yang umumnya dianggap sebagai pendiri cabang linguistik. Akan tetapi, pengaruh tersebut tidak hanya terhenti sebatas wilayah linguistik tetapi juga pada dimensi-dimensi budaya yang lebih luas. Mengklaim bahasa Arab adalah satu-satunya bahasa Islam menjadi tidak sederhana jika hal tersebut dikaitkan dengan kontestasi negara-negara yang dalam sejarahnya telah 
ISSN : $1829-8257$

STAIN Palangka Raya

cukup dominan dalam pengembangan Islam. Sebagai sebuah kajian sosiologi Agama, hal tersebut menjadi lahan penelitian yang terbuka luas untuk terus diamati dalam tingkat praktek berbahasa masyarakat-masyarakat di mana Islam menjadi agama mayoritas.

\section{Daftar Pustaka}

Bahar. M.T.1942. Sabk Shinasi (A Study of Styles). 3 vols. Tehran

Bussmann, H. 2006. Routledge Dictionary of Language and Linguistics.Taylor \& Francis e-Library, London and New York

Crystal, D. 1966. Language and Religion. In L. Sheppard (ed), Twentieth century Catholicism. Hawthorn Books, New York

Downes, W. 2011.Language and Religion: A Journey into the Human Mind, Cambridge University Press, New York

Fishman, J. A. 2006. A Decalogue of Basic Theoretical Perspectives for a Sociology of Language and Religion. In: Omoniyi, T. and Fishman, J. A. (eds.). Explorations in the Sociology of Language and Religion. John Benjamins Publishing Company, Amsterdam/Philadelphia

James W. 1902.The Varieties of Religious Experience:A Study in Human Nature. NewYork: Longman Green

Khan, M.A.M. 2011.Role of Mother Language in Islam. Independent Publications Limited, Dhaka

Kramer, M.1989.The Political Language of Islam. Middle East Review

McAuliffe,J. D. 2001. Preface. In: McAuliffe,J. D., et.al (eds.). Encyclopaedia of the Qur_ān: Volume One A-D. Brill, Leiden-Boston-Koln: i-xiii

Al-Munajjid, S.M.S. (a) 2011. Fatwa No. 114639. Islam QA. http://www.islamqa.com/en/ref/114639

-(b). 2011. Fatwa No. 20953. Islam QA. http://www.islamqa.com/en/ref/20953

Phyllis Ghim-Lian Chew. 2006. Language Use and Religious Practice:The Case of Singapore. In: Explorations in the Sociology of Language and Religion. John Benjamins Publishing Company, Amsterdam/Philadelphia

Pandharipande, R. V. 2006. Ideology, Authority, and Language Choice: Language of Religion in South Asia. In: Explorations in the Sociology of Language and Religion. John Benjamins Publishing Company, Amsterdam/Philadelphia 
2010. Authenticating a Tradition in Transition: Language of Hinduism in the US. In: Omoniyi, T. (ed.). The Sociology of Language and Religion: Change, Conflict and Accommodation. Palgrave Macmillan, New York

Putra, I.N.A.J. 2009. The Use of Code by the Moslem Speech Community of Pegayaman: A Sociolinguistic Study. E-Journal of Linguistics, No. 1. Department of Linguistics, Faculty of Letters, Udayana University, Bali

Rajah-Carrim, A. 2010.Mauritian Muslims: Negotiating Changing Identities through Language. In: Omoniyi, T. (ed.). The Sociology of Language and Religion: Change, Conflict and Accommodation. Palgrave Macmillan, New York

Salami, O. 2010.Arabic and Sociocultural Change among the Yoruba. Dalam: Omoniyi, T. (ed.). The Sociology of Language and Religion Change, Conflict and Accommodation. New York: Palgrave Macmillan.

Singh, K. G. 2011. Contribution of Turkic Languages in the Evolution and Development of Hindustani Languages.Turkish Digest.

Smolicz, J.J. 1994. Multiculturalism, Religion and Education.Education and Society. 12(1): 22-47.

Taliaferro, C. 2005. Evidence and Faith: Philosophy and Religion since the Seventeenth Century. New York: Cambridge University Press

Wallace AFC. 1966. Religion: An AnthropologicalView. New York: Random House

Woods, A. 2004.Medium or Message?Language and Faith in Ethnic Churches.Multilingual Matters Ltd, Clevedon, Buffalo, Toronto, Sydney 